\title{
Grinding titanium alloys applying small quantity lubrication
}

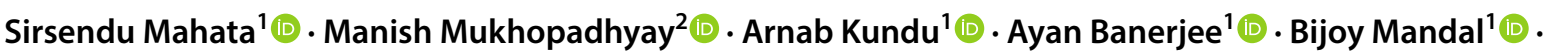 \\ Santanu Das ${ }^{1}$ (1)
}

Received: 1 November 2019 / Accepted: 17 April 2020 / Published online: 28 April 2020

(c) Springer Nature Switzerland AG 2020

\begin{abstract}
Rapid progress of manufacturing industry intends to evolve an appropriate method to shape advanced materials, such as titanium and its alloys, with improved properties. Enhanced strength at elevated temperatures in addition to superior corrosion resistance and biocompatibility have made titanium a popular metal employed in manufacturing, petroleum, automobile, aerospace and medical industries. Although having relatively greater abundance than many metals, processing, machining and grinding of titanium are difficult. The present experimental investigation explores the effectiveness of the indigenously developed small quantity lubrication (SQL) technique using soap water along with liquid $\mathrm{CO}_{2}$ jet cooling technique. Variations in grinding forces, surface roughness, grinding ratio, chip form and surface morphology observed indicate that applying SQL along with liquid $\mathrm{CO}_{2}$ jet is much effective in improving grindability of Grade 5 and Grade 1 titanium alloys than dry grinding and grinding using liquid $\mathrm{CO}_{2}$ jet alone.
\end{abstract}

Keywords Grinding $\cdot$ Liquid $\mathrm{CO}_{2}$ coolant $\cdot$ Cryogenic cooling $\cdot \mathrm{SQL} \cdot$ Titanium

\section{Introduction}

Grinding is a surface finishing process where material removal takes place by randomly and stochastically distributed abrasive particles. This process is extensively used in manufacturing industries for making products with close tolerances, high precision and high surface quality. In grinding, material removal takes place by the combination action of shearing, ploughing and rubbing, and results in the formation of tiny chips [1]. Precision and surface finish obtained through this process can be up to ten times better than that of other conventional machining processes like turning or milling [2-4]. Grinding, done at a high speed, requires large force per unit volume of material removed, and generates high heat which may cause surface burn and redeposition of chips on the ground surface. Shaw and Vyas [5] suggested that heat generated in the contact area between wheel and workpiece is the main cause of deterioration in the metallurgical properties of the workpiece, dimensional accuracy and wheel life. Apart from that, intense wheel loading and wheel material removal are possible adverse effects of the process [6-9]. To reduce or control these adversities, proper application of cutting fluid is important. Adoption of special and effective techniques of fluid delivery like multi-nozzle cooling system $[1,2,10]$, rexine-pasted wheel [11], pneumatic barrier [12], painted wheel technique [1, 2, 12], etc. may be undertaken.

Rapid advancement of material science and technology facilitated discovery of new elements, metals and alloys having high hardness, strength, ductility, toughness and low thermal conductivity, thereby making them difficult to machine $[13,14]$. Such metals/alloys not only possess the ability to withstand elevated temperature, but also retain

Manish Mukhopadhyay, manishmukhopadhyay@gmail.com; Sirsendu Mahata, mahatasirsendu@gmail.com; Arnab Kundu, arnab.092014@gmail.com; Ayan Banerjee, ayan.092063@gmail.com; Bijoy Mandal, bijoymandal@gmail.com; Santanu Das, sdas.me@gmail.com | 1'Mechanical Engineering Department, Kalyani Government Engineering College, Nadia, West Bengal 741235, India. ${ }^{2}$ Mechanical Engineering Department, Meghnad Saha Institute of Technology, Kolkata, West Bengal 700150, India. 
their integrity with minimum environmental impact [15]. Titanium is one such material. Past experiments showed that about $80 \%$ of the heat generated while machining titanium alloy $\mathrm{Ti}-6 \mathrm{Al}-4 \mathrm{~V}$ was conducted into the tool due to low thermal conductivity of titanium alloys, which is about 1/6th of that of steel [16], thereby increasing the challenges in machining. Additionally, its high strength maintained at elevated temperature and its low modulus of elasticity were reported to impair its machinability further [17]. The effective way to improve grindability of such materials might be through the application of cutting fluids $[2,18]$. However, use of excessive amount of cutting fluid results in increased processing cost, storage problem, disposal problem, environmental degradation, health hazard to operator, impaired machining system, etc. [19]. MQL poses itself as an effective solution to counter this problem [20-27].

MQL that stands for minimum quantity lubrication is a set of coolant delivery techniques that focuses on reduction of cutting fluid consumption without sacrificing the productivity of the process. Javaroni et al. [28] applied MQL for grinding of advanced ceramics. They reported much satisfactory results for grinding under MQL conditions at different flow rates compared to conventional coolant delivery technique. Sato et al. [29] analysed the influence of water addition during grinding of AISI 4340 steel using $\mathrm{CBN}$ grinding wheel. They reported that with increased dilution by adding water, grinding conditions were improved for processing the material. Clogging effect also reportedly decreased with the addition of water. Rodriguez et al. [30] reported that for surface grinding of carbon fibre-reinforced plastic (CFRP) composites, the $M Q L$ technique required the lowest grinding force and specific energy. Lopez et al. [31] used MQL under cold air for grinding of hardened steel. They reported that MQL using cold air jet along with wheel cleaning system provided the most satisfactory grinding performance and recommended the process to be the most suitable for application in the industries. Morares et al. [32] applied MQL technique for grinding SAE 52100 with pure and diluted oil as cutting fluid. The results of the water increment in the MQL were found superior to that of the MQL (oil-pure) in almost all aspects, remaining inferior only in the cutting power. Francelin et al. [33] used MQL delivery technique for cylindrical plunge grinding using $c B N$ wheel of AISI 4340 steel. They reported that the MQL technique required a smaller wheel replacement interval due to lower wear than that obtained by the conventional technique. Researchers have been using the term MQL for quite some time. Typical flow rate in MQL system ranges from 10 to $100 \mathrm{ml} / \mathrm{h}$ after Sadhegi et al. [34]. However, the term 'minimum' is ambiguous. How can one achieve minimum flow rate is the question. Some other person can use lower than the so-called 'MQL' amount of grinding fluid also. Still this terminology is being used by the researchers and others to mean the use of quite low quantity of fluid. However, some research groups preferred using the more logical term, SQL (small quantity lubrication) than MQL. Although MQL/SQL proved to be an effective delivery strategy, however, the use of low temperature coolant along with the MQL technique may further enhance the grindability of any material [35]. Mukhopadhyay, Kundu and Das performed [14] an experimental work on grindability of Ti-6Al-4V using alkaline soap water under flood cooling and also using SQL in the form of a coolant jet. They observed substantial improvement in terms of lower force requirement and surface roughness; improvement in grinding ratio and surface quality was also reported in favour of SQL-based cutting fluid delivery technique. Mukhopadhyay and Kundu [36] employed SQL-based drop-bydrop method during grinding of Ti-6Al-4V and compared the result with dry grinding and grinding under flood cooling. The results suggested that grinding ratio improved by 1.5 times, and the average surface roughness reportedly reduced by around $58 \%$ over dry grinding. Grinding under SQL using drop-by-drop method when compared to grinding under flood cooling resulted in grinding ratio to have been improved by 1.3 times. Similar improvement in grindability of titanium alloy was also reported by Kundu et al. [37] through a comparative performance analysis of SQL using drop-by-drop method and dry grinding. Ghorai et al. [38] performed an experimental investigation where they employed drop-by-drop method of SQL to determine suitable coolant concentration of sodium nitrite solution. The results suggested that grindability of titanium alloys improved with increasing coolant concentration.

Venugopal, Paul and Chattopadhyay $[39,40]$ reported the use of cryogenic liquid nitrogen that resulted in substantial rise in cutting tool life through minimising adhesion-dissolution-diffusion tool wear for turning titanium alloy. An et al. [41] applied a cold air jet at $-20^{\circ} \mathrm{C}$ and inferred subsequent rise in grindability of titanium alloys. On the contrary, Tiecher and his co-researchers $[42,43]$ reported cryogenic liquid nitrogen jet to have a minimal effect for improving grinding performance of Ti-6Al-4V. They rather vouched for alkaline-based coolants to be more effective than others. Elanchezhian, Kumar and Manimaran [44] experimentally proved the positive effect of cryogenic grinding of Ti-6Al-4V over conventional wet grinding. A substantial decrease in grinding force and surface roughness was reported, employing cryogenic coolant. Gupta and Laubscher [45] proposed the MQL-assisted cryogenic cooling as the most effective solution to improve machining and grinding performance of titanium alloys. 
The present experiment is aimed at finding the effectiveness of the developed SQL-assisted liquid $\mathrm{CO}_{2}$ coolant delivery setup for grinding titanium alloys using a silicon carbide wheel in up-grinding mode with $10 \mu \mathrm{m}$ infeed. Titanium grade $5(\mathrm{Ti}-6 \mathrm{Al}-4 \mathrm{~V})$ and titanium grade 1 (Cp-Ti) are employed as workpiece materials. Silicon carbide wheel is chosen due to its higher friability and suitability for processing titanium alloys $[46,47]$. The liquid $\mathrm{CO}_{2}$ jet has been delivered at a temperature of $-26^{\circ} \mathrm{C}$ at the grinding zone. Identical sets of experiments are performed on both materials under different conditions viz. dry, grinding using liquid $\mathrm{CO}_{2}$ and grinding using SQLassisted liquid $\mathrm{CO}_{2}$. Alkaline soap water is chosen as the $\mathrm{SQL}$ coolant. Both the liquid $\mathrm{CO}_{2}$ coolant and the SQL system using soap water were found to prove its worth in the past research works as reported by Kundu et al. [48] and Mukhopadhyay and Kundu [49].

\section{Materials and method}

In the present experimental investigation, plunge surface grinding of grade 5 and grade 1 titanium alloy has been performed in up-grinding mode for 20 passes under different environmental conditions. The work material used are in the form of flats having dimension of $120 \mathrm{~mm} \times 60 \mathrm{~mm} \times 6 \mathrm{~mm}$. Grinding has been performed on the side having a thickness of $6 \mathrm{~mm}$ for ease of estimation of wheel wear. The SQL system was developed recently by Mukhopadhyay and Kundu [49] and results obtained proved the superiority of the used SQL technique over flood cooling. The alkaline coolant was reported to provide enhanced anti-frictional nature in the grinding zone and resulted in lesser wheel loading [12]. This, in turn, resulted in reduction of cutting forces and generated smoother surface with reduced average surface roughness [12]. Liquid $\mathrm{CO}_{2}$ is chosen as coolant because of its easy availability and comparatively lower cost than liquid nitrogen. The schematic of the setup is shown in Fig. 1. Grindability is assessed on the basis of variation of grinding force, surface roughness, grinding ratio, chip form and surface morphology observed.

Table 1 contains the experimental details for the present investigation. Measurement of wheel material removal and workpiece material removal is done with the help of dial gauge (Mitutoyo Japan make, least count: $10 \mu \mathrm{m}$ ) and digital vernier height gauge (Mitutoyo Japan make, least count: $1 \mu \mathrm{m}$ ), respectively. Volume of work material was determined by measuring the depth of the material removed (using height gauge) and then multiplying it with width $(6 \mathrm{~mm})$ and length $(120 \mathrm{~mm})$ of the workpiece. Volume of wheel material is found out by measuring the depth of wheel material removed (using a dial gauge)

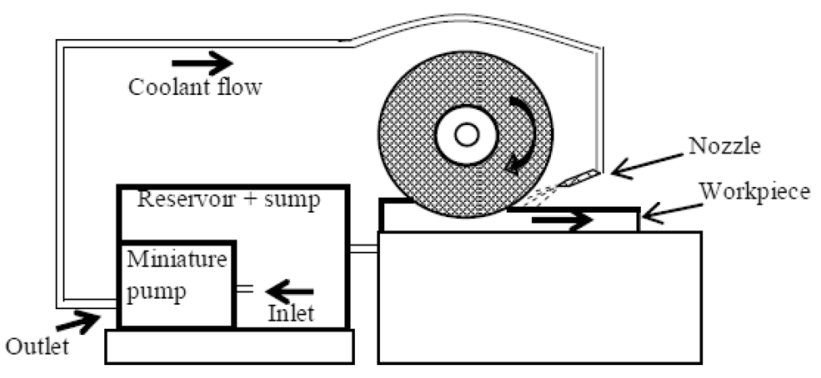

Fig. 1 Schematic of the SQL using miniature pump setup (Mukhopadhyay and Kundu [49])

and multiplying it with the width of the groove and the peripheral distance.

\subsection{Cooling using liquid $\mathrm{CO}_{2}$}

This arrangement as shown in Fig. 2a is made to apply liquid food-grade $\mathrm{CO}_{2}$ as coolant. Liquid $\mathrm{CO}_{2}$ has been applied directly from the cylinder, through a nozzle to the grinding zone. The exit pressure was chosen as $3 \mathrm{~kg} /$ $\mathrm{cm}^{2}$ enabling the $\mathrm{CO}_{2}$ jet to effectively penetrate the stiff air layer formed around the grinding wheel and to strike the grinding zone. Stiff air layer is generated around the periphery of the porous grinding wheel rotating at a high speed.

\subsection{SQL-assisted liquid $\mathrm{CO}_{2}$ cooling setup}

This arrangement is a combination of liquid $\mathrm{CO}_{2}$ and cooling using a miniature pump in SQL mode as shown in Fig. 2b, c. Here, coolant through miniature pump is applied along with liquid $\mathrm{CO}_{2}$ having the same specifications as detailed in Table 1. Alkaline soap water solution is used as coolant pumped as a jet through a nozzle of $1.21 \mathrm{~mm}$. The miniature pump-based SQL system used is economical and efficient [49]. Both the nozzles are directed in the direction in which the grinding wheel rotates. The combined liquid $\mathrm{CO}_{2}$ and liquid coolant solution pumped in SQL mode penetrate the stiff air layer and impinge on the grit-workpiece interface.

\section{Results and discussion}

Grinding forces, surface roughness, grinding ratio, surface morphology and chip forms are analysed thoroughly, and the factors responsible for improvement in grindability are reported. Variation of grinding forces, viz. normal force $\left(F_{n}\right)$ and tangential force $\left(F_{\mathrm{t}}\right)$ components for the two materials under different environmental conditions are shown in Figs. 3 and 4. Grinding force requirement is measured with 
Table 1 Experimental details

Surface grinding machine

Grinding wheel

Work material

Machining parameters

Grinding environment

Force dynamometer

Wheel dresser

Surface roughness tester

Stereo microscope
Make: HMT, Praga division; Model: $452 \mathrm{P}$; Infeed resolution: $1 \mu \mathrm{m}$; Power: $1.5 \mathrm{~kW}$; Spindle speed: $2800 \mathrm{rpm}$

Make: Carborundum universal limited; Type: Disc type; Size: $\phi 200 \mathrm{~mm} \times \phi 31.75 \mathrm{~mm} \times 20 \mathrm{~mm}$ thick: Specification: CGC $60 \mathrm{~K} 5 \mathrm{~V} 8$

Grade 5:

Type: Ti-6Al-4V

Composition: $\mathrm{Ti}-88.77 \%$; $\mathrm{Al}-6.19 \%$; V-4.25\%;

$\mathrm{Fe}-0.34 \%$; Traces- $0.45 \%$

Dimension: $120 \mathrm{~mm} \times 60 \mathrm{~mm} \times 6 \mathrm{~mm}$

Hardness: 32 HRC

Grade 1 (commercially pure titanium-Cp-Ti):

Type: Titanium grade 1

Composition: Ti-97.86\%; $\mathrm{Al}-1.39 \%$; $\mathrm{Fe}-0.42 \%$;

Mo-0.24\%; Traces- $0.09 \%$

Dimension: $120 \mathrm{~mm} \times 60 \mathrm{~mm} \times 6 \mathrm{~mm}$

Hardness: 22 HRC

Cutting velocity: $30.2 \mathrm{~m} / \mathrm{s}(1810 \mathrm{~m} / \mathrm{min})$

Feed: $14 \mathrm{~m} / \mathrm{min}$

Infeed: $10 \mu \mathrm{m}$

Dry

Liquid $\mathrm{CO}_{2}$ jet

Type: Liquid $\mathrm{CO}_{2}$ (food-grade) along with micropump

Nozzle diameter: $3.25 \mathrm{~mm}$; Coolant: $\mathrm{CO}_{2}$ gas

Cylinder pressure: $70 \mathrm{~kg} / \mathrm{cm}^{2}$; Release pressure: $3 \mathrm{~kg} / \mathrm{cm}^{2}$

Release temperature: $-26^{\circ} \mathrm{C}$

$\mathrm{SQL}$-assisted liquid $\mathrm{CO}_{2}$ jet

Liquid $\mathrm{CO}_{2}$ Jet Setup

Type: Liquid $\mathrm{CO}_{2}$ (food-grade) along with micropump

Liquid $\mathrm{CO}_{2}$ Nozzle diameter: $3.25 \mathrm{~mm}$

Coolant: $\mathrm{CO}_{2}$ gas

Cylinder pressure: $70 \mathrm{~kg} / \mathrm{cm} 2$; Release pressure: $3 \mathrm{~kg} / \mathrm{cm}^{2}$

Release temperature: $-26^{\circ} \mathrm{C}$

SQL using miniature pump setup

Pump Specs: Make-Sobo, India

Power: $10 \mathrm{~W}$

SQL Nozzle diameter: $1.21 \mathrm{~mm}$; Coolant: soap water

Mixture: Clinic plus shampoo and water; Mixing ratio: $1: 20$ by volume

Flow rate: $210 \mathrm{ml} / \mathrm{min}$

Make: Sushma grinding dynamometer, Bengaluru Model: SA 116;

Range: $0.1-100 \mathrm{~kg}$;

Resolution: $100 \mathrm{~g}$

Make: Norton Abrasives, India

Specification: 0.75 carat single point diamond tip Dressing infeed: $20 \mu \mathrm{m}[50,51]$

Dressing Speed: $30 \mathrm{~mm} / \mathrm{s}$

Make: Mitutoyo, Japan; Model: Surftest 301

Range: 0.05-40 $\mu \mathrm{m}$; Resolution: $0.05 \mu \mathrm{m}$

Make: Gippon, Japan

Magnification: $20 \times$ to $40 \times$ 
Fig. 2 a Liquid $\mathrm{CO}_{2}$ cooling setup; b SQL-assisted liquid $\mathrm{CO}_{2}$ cooling setup and $\mathbf{c}$ magnified view of the SQL-assisted liquid $\mathrm{CO}_{2}$ cooling setup
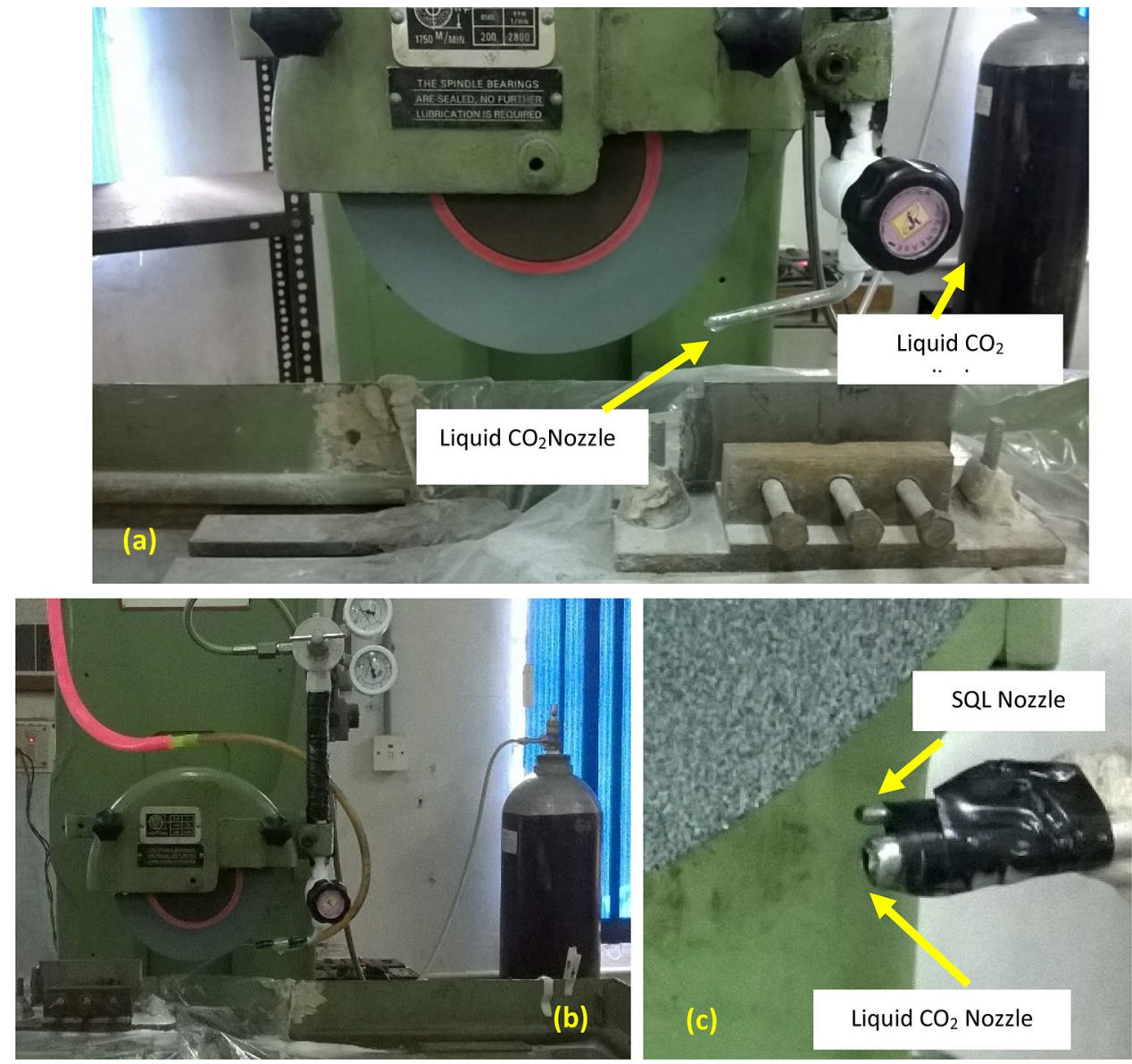

a strain gauge type dynamometer for 20 passes during each set of experiment.

A general trend observed in both Figs. 3 and 4 is that normal force is always found to be greater than tangential force. This may be due to the inherent random orientation of the abrasive grits which predominantly have high negative rake angle. The grit orientation enables rubbing and ploughing to be dominant form of grit-workpiece interaction rather than shearing effect that is desired. The trend observed in the variation of grinding force is following similar progression for both the materials. Force requirement while grinding titanium grade 5 is slightly greater than that of titanium grade 1, because of the presence of alloying elements i.e. aluminium and vanadium, respectively, as $a$ and $\beta$ stabilizers, which make the material harder than commercially pure titanium grade 1 .

Generally, grinding in dry condition is expected to require greater amount of force for material removal, obviously due to the absence of lubrication and cooling, however, it is observed that using liquid $\mathrm{CO}_{2}$ as coolant, force required for material removal is more than that during dry grinding. It corroborates the inferences made by some researchers that give unfavourable decisions for cryogenic cooling during grinding titanium alloys [35]. A possible reason for this may be that as liquid $\mathrm{CO}_{2}$ jet provides a temperature as low as $-26^{\circ} \mathrm{C}$, it serves as a quenching medium to the heated-up substrate. Hence, exposure to liquid $\mathrm{CO}_{2}$ during grinding operation increases its surface hardness instantaneously, thereby enhancing cutting force requirement. Introduction of alkaline soap water jet through miniature pump setup along with liquid $\mathrm{CO}_{2}$ jet proves to be effective in reducing the high force requirement in the previous two setups. This method is found to be efficient for both titanium grade 5 and titanium grade 1. It is a known fact that hardening of a material can result in ease of machining since excessive ductile materials may be difficult to machine owing to its stickiness under heated condition. Thus, liquid $\mathrm{CO}_{2}$ jet helps in increasing grindability and with the introduction of alkaline coolant jet, the system is supplied with enhanced lubrication that cools and subsequently reduces grinding force requirement. To understand the characteristics in a better way, surface roughness and grinding ratio are the two important parameters that are considered.

Average surface roughness $\left(R_{\mathrm{a}}\right)$ is measured with the aid of Surftest-301 of Mitutoyo make. The results shown in Fig. 5 are the average of five $R_{\mathrm{a}}$ values taken at different locations on the ground surface in the direction 

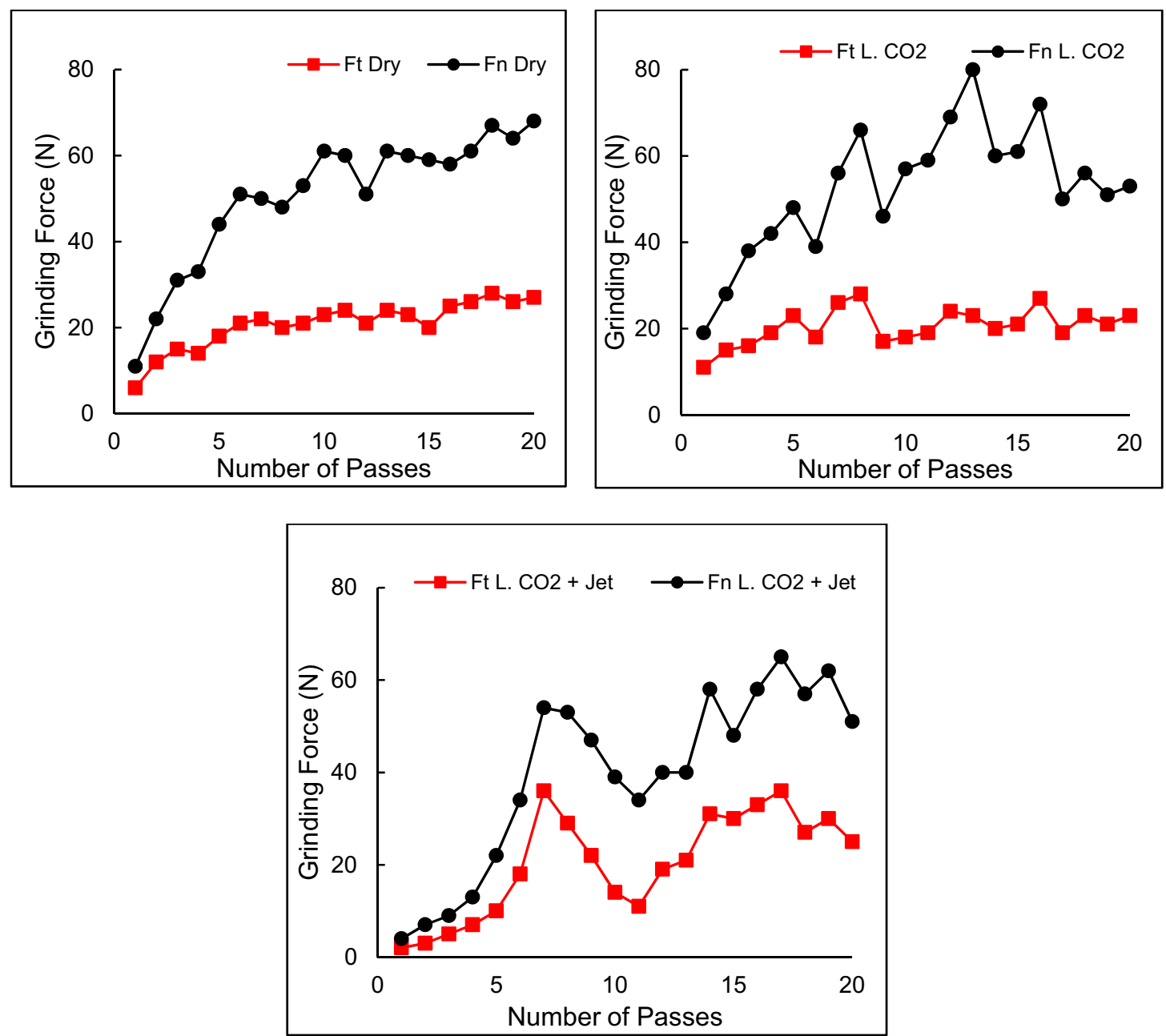

Fig. 3 Variations of grinding force for 20 passes under different environmental conditions while grinding titanium grade 5, a dry grinding, $\mathbf{b}$ grinding under liquid $\mathrm{CO}_{2}$ and $\mathbf{c}$ grinding under liquid $\mathrm{CO}_{2}+$ liquid jet

perpendicular to the grinding lay marks. The highest surface roughness is observed for dry grinding, quite understandably due to the absence of cooling and lubrication. Introduction to liquid $\mathrm{CO}_{2}$ as coolant is not effective for reducing grinding force. However, the condition proves to be effective for improving surface quality. This may be due to the retention of grit sharpness as liquid $\mathrm{CO}_{2}$ jet helps to provide sub-zero temperature and avoids plastic deformation of the cutting tips (occurring due to high cutting temperatures). An abnormality has been observed in case of grinding grade 1 titanium alloy in which $R_{a}$ value is found to be higher than that in dry grinding. This might have happened due to excessive rubbing and ploughing action during dry grinding which creates polishing action to take place, as the grits undergo glazing, thereby reducing grit sharpness. This may have resulted in decrease in surface roughness in dry grinding to a small extent than that with liquid $\mathrm{CO}_{2}$. Surface roughness has decreased further with the application of alkaline coolant jet in combination with liquid $\mathrm{CO}_{2}$ jet owing to more effective cooling and lubrication provided by this setup. Grit sharpness retention capability is expected to be much superior in this case. This has been further supported by grinding ratio obtained under different environmental conditions for both grade 5 and grade 1 titanium as shown in Fig. 6.

Grinding Ratio $=\frac{\text { Volume of work material removed }}{\text { Volume of wheel material removed }}$

Grinding ratio is determined by measuring the volume of wheel material and workpiece material removed, after completion of 20 grinding passes at each environmental condition. A clear trend that can be observed from the values shown in Fig. 6 suggests that with the application of cutting fluid, improvement in lubrication and cooling is observed, thus, grinding ratio increases. Dry grinding 

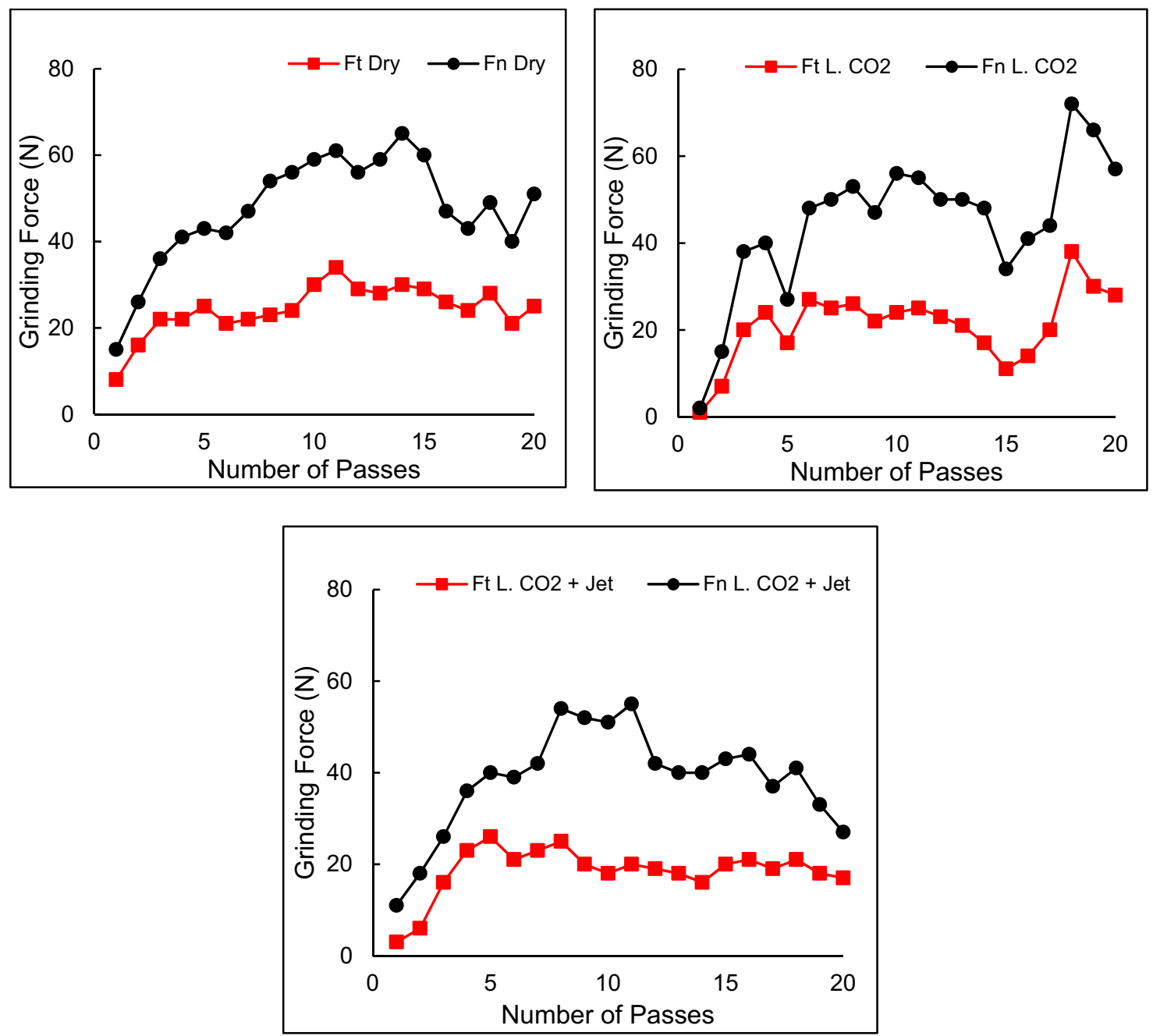

Fig. 4 Variations of grinding force for 20 passes under different environmental conditions while grinding titanium grade 1, a dry grinding, b grinding under liquid $\mathrm{CO}_{2}$ and $\mathbf{c}$ grinding under liquid $\mathrm{CO}_{2}+$ liquid jet

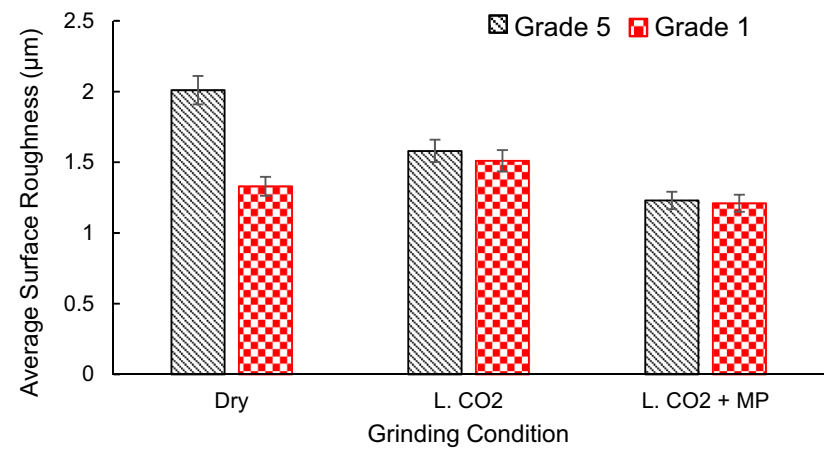

Fig. 5 Average surface roughness values $(\mu \mathrm{m})$ during different grinding environments

renders the lowest grinding ratio due to the absence of lubrication causing generation of high heat and frictional forces that ultimately results in excessive wheel material

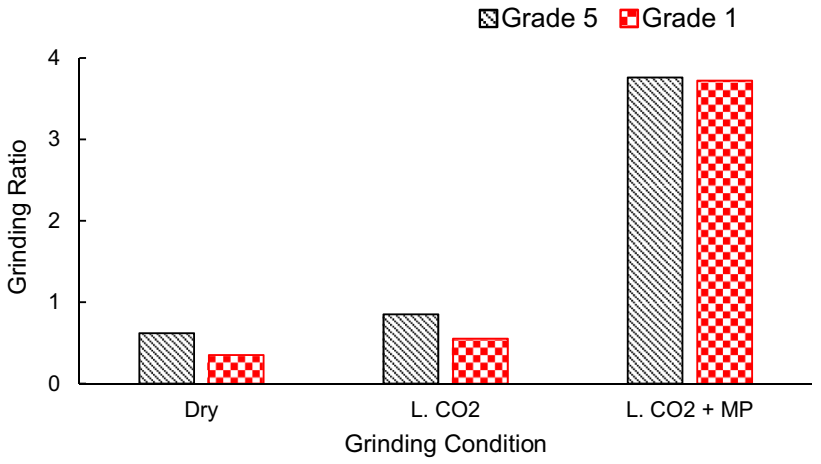

Fig. 6 Grinding ratio measured during different grinding conditions

loss. Application of liquid $\mathrm{CO}_{2}$ as coolant has not proved to be much effective in increasing grinding ratio. However, with the combination of liquid $\mathrm{CO}_{2}$ and alkaline soap water 
jet, grinding ratio shows remarkable improvement. Almost 4-5 times increase in grinding ratio has been observed which reiterates the efficacy of the delivery system.

Figure 7 and Fig. 8 show observed chip forms obtained during the $20^{\text {th }}$ pass for different grinding conditions under a high resolution stereo microscope. From Fig. 8, it is observed that chips obtained in case of dry grinding are larger in size and are of blocky or segmented types. This is due to the absence of coolant in dry grinding. High heat generation in dry grinding results in melting and subsequent amalgamation of loaded chips in intergrit spaces to form larger chunks of blocky chips. Chips obtained in case of grinding with liquid $\mathrm{CO}_{2}$ are also considerably larger in size. This, again, is likely to be due to the absence of lubrication which results in greater rubbing and ploughing action giving rise to wheel loading, thereby forming chips of relatively bigger size. With the introduction of alkaline coolant jet along with liquid $\mathrm{CO}_{2}$ jet, grinding chips obtained show a favourable trend as far as shape and size are concerned. Majority of chips obtained are of curled or flowing/leafy type, which show improvement in shearing action and decrease in rubbing and ploughing. As far as ground surface quality is concerned, Figs. 9 and 10 give an impression of the presence of scar, cracks, crater, redeposition, etc. in dry grinding and also while grinding using liquid $\mathrm{CO}_{2}$ as coolant. Ground surface quality is found to improve significantly when alkaline coolant jet is used along with liquid $\mathrm{CO}_{2}$ jet which provides improved ground surface. However, advanced characterisation of the surface using scanning electron microscopy (SEM) would have made more clear depiction of the surface characteristics.

\section{Conclusions}

Grinding of titanium alloys using three grinding conditions viz. dry grinding, grinding using liquid $\mathrm{CO}_{2}$ and using alkaline fluid jet combined with liquid $\mathrm{CO}_{2}$ jet with silicon carbide wheel reveals that:

- Grinding using the $\mathrm{SQL}$ and liquid $\mathrm{CO}_{2}$ setup results in considerable reduction of grinding forces due to better lubrication and cooling effect achieved along with effective penetration of the coolant in the grinding zone.

- SQL and liquid $\mathrm{CO}_{2}$ combined arrangement also provides better surface finish and generates the ground surface devoid of any visible defects. Improvement in grinding ratio by $4-5$ times than dry grinding is also achieved.

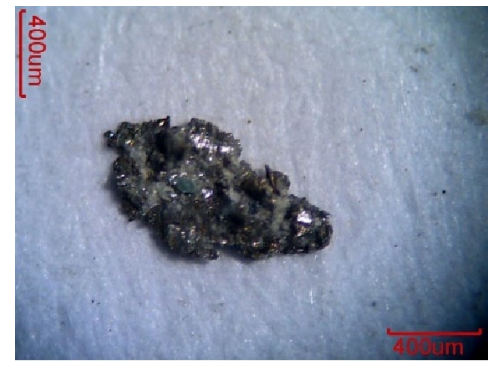

(a) Dry Grinding

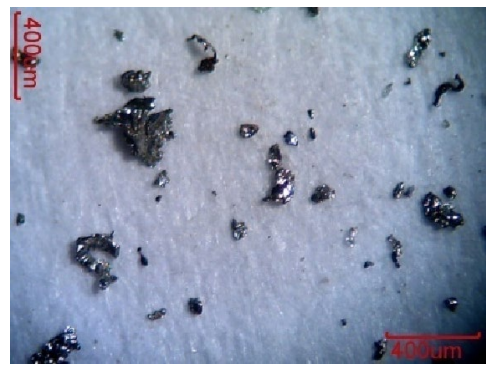

(b) using liquid $\mathrm{CO}_{2}$

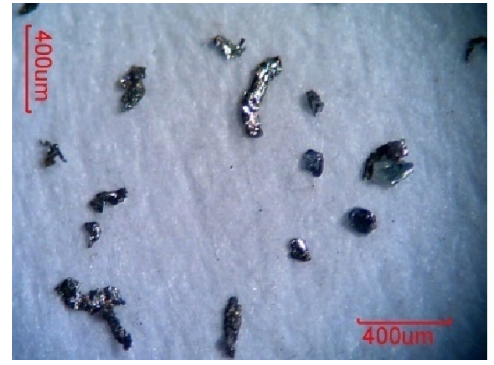

(c) using liquid $\mathrm{CO}_{2}+$ jet

Fig. 7 Grinding chips observed under different environmental condition using a stereo microscope while grinding titanium grade 5

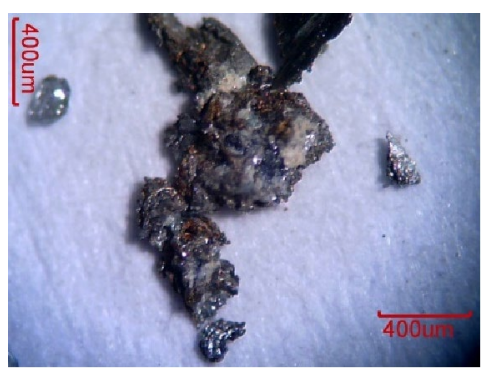

(a) Dry Grinding

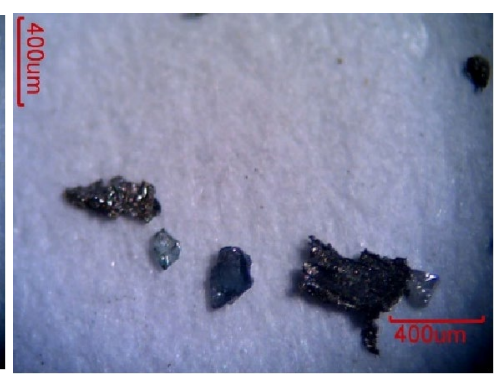

(b) using liquid $\mathrm{CO}_{2}$

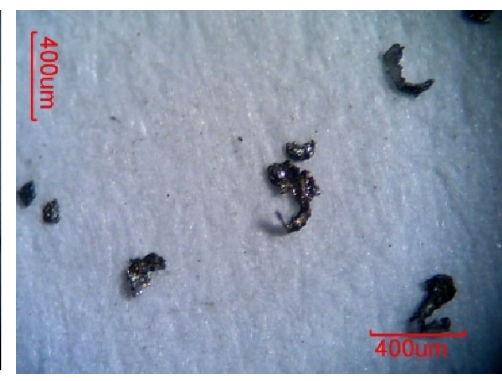

(c) using liquid $\mathrm{CO}_{2}+$ jet

Fig. 8 Grinding chips observed under different environmental condition using a stereo microscope while grinding titanium grade 1 


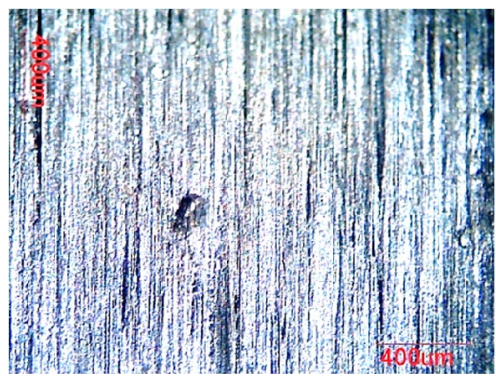

(a) Dry Grinding

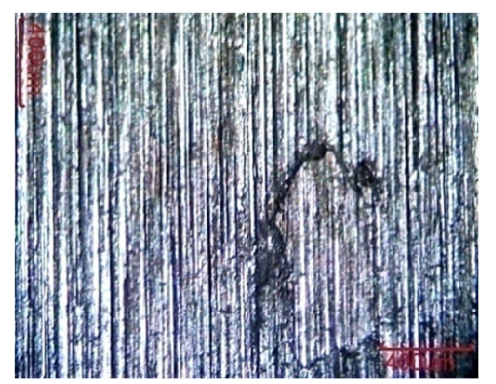

(b) using liquid $\mathrm{CO}_{2}$

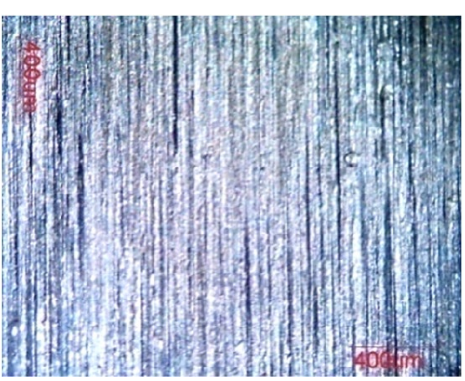

(c) using liquid $\mathrm{CO}_{2}+$ jet

Fig. 9 Ground surface morphology observed under different environmental condition using a stereo microscope while grinding titanium grade 5

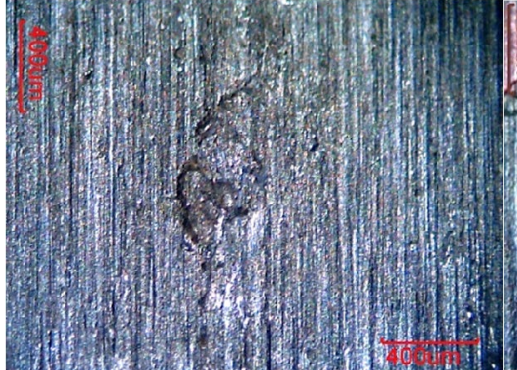

(a) Dry Grinding

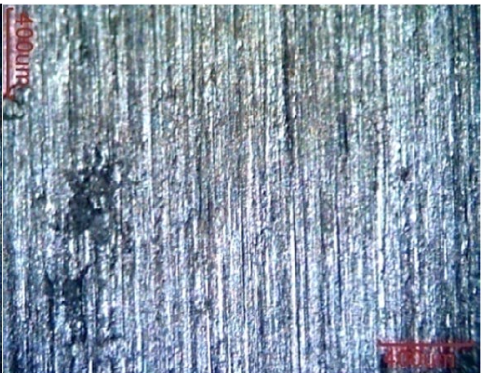

(b) using liquid $\mathrm{CO}_{2}$

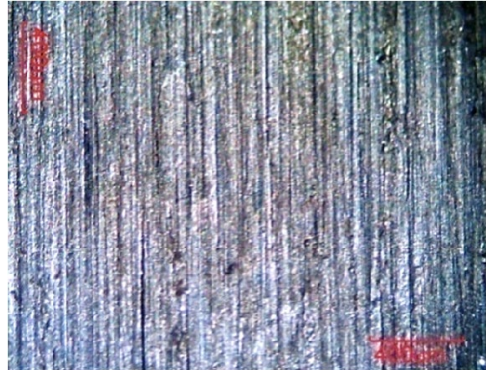

(c) using liquid $\mathrm{CO}_{2}+$ jet

Fig. 10 Ground surface morphology observed under different environmental condition using a stereo microscope while grinding titanium grade 1

- A thorough study considering different parameters reveals that sub-zero cooling alone is not suitable for grinding titanium alloys. However, if small amount of alkaline-based coolant can be mixed with this sub-zero coolant jet, then the positive effect of both the coolants can be optimally utilised.

\section{Compliance with ethical standards}

Conflict of interest On behalf of all authors, the corresponding author states that there is no conflict of interest.

\section{References}

1. Malkin S, Guo C (2008) Grinding technology: theory and applications of machining with abrasives. Industrial Press, New York

2. Malkin S, Guo C (2007) Thermal analysis of grinding. CIRP Ann Manuf Technol 56(2):760-782. https://doi.org/10.1016/j. cirp.2007.10.005

3. Mukhopadhyay M, Kundu PK (2019) Enhancing grindability of Ti-6Al-4V applying ecological fluidsunder SQL using SiC wheel. SN Appl Sci 1(600):1-8. https://doi.org/10.1007/s4245 2-019-0616-Z

4. Guo G, Liu Z, An Q, Chen M (2011) Experimental investigation on conventional grinding of Ti-6Al-4V using $\mathrm{SiC}$ abrasive. Int J Adv Manuf Technol 57:135-142. https://doi.org/10.1007/s0017 0-011-3272-z

5. Shaw MC, Vyas A (1994) Heat-affected zones in grinding steel. CIRP Ann Manuf Technol 43(1):279-282. https://doi. org/10.1016/S0007-8506(07)62213-6

6. Majumdar S, Kumar S, Chakraborty S, Roy D (2017) Effective application of scraper board in grinding. Tribol Int 116:120-128. https://doi.org/10.1016/J.TRIBOINT.2017.07.009

7. Malkin S, Guo C (2007) Thermal analysis of grinding. CIRPAnn Manuf Technol 56(2):760-782. https://doi.org/10.1016/j. cirp.2007.10.005

8. Lee CW, Shin YC (2004) Modeling of complex manufacturing processes by hierarchical fuzzy basis function networks with application to grinding processes. J Dyn Syst Meas Control 126:880-890. https://doi.org/10.1115/1.1849247

9. Saglam H, Unsacar F, Yaldiz S (2005) An experimental investigation as to the effect of cutting parameters on roundness error and surface roughness in cylindrical grinding. Int J Prod Res 43:2309-2322. https://doi.org/10.1080/00207540412331330110

10. Mahata S, Mistri J, Mandal B, Das S (2013) A comparative study of grinding performance using different fluid delivery technique. J Assoc Eng India 83:63-70. https://doi.org/10.22485/jaei\%2F201 3\%2Fv83\%2Fi3-4\%2F119929

11. Mandal B, Das GC, Das S, Banerjee S (2014) Improving grinding fluid delivery using pneumatic barrier and compound 
nozzle. Prod Eng 8:187-193. https://doi.org/10.1007/s1174 0-013-0507-x

12. Mandal B, Majumdar S, Das S, Banerjee S (2011) Formation of a significantly less stiff air-layer around a grinding wheel pasted with rexine leather. Int J Precis Technol 2:12-20. https://doi. org/10.1504/IJPTECH.2011.038106

13. Mukhopadhyay M, Kundu PK (2019) Evaluating applicationpotentiality of unconventional fluids for grinding Ti-6Al$4 \mathrm{~V}$ using alumina wheel. Mater Manuf Process. https://doi. org/10.1080/10426914.2019.16150

14. Mukhopadhyay M, Kundu PK, Das S (2018) Experimental investigation on enhancing grindability using alkaline-based fluid for grinding Ti-6Al-4V. Mater Manuf Process 33(16):17751781. https://doi.org/10.1080/10426914.2018.1476759

15. Ahmed LS, Kumar MP (2016) Cryogenic drilling of Ti-6Al-4V alloy under liquid nitrogen cooling. Mater Manuf Process 31:951-959. https://doi.org/10.1080/10426914.2015.1048475

16. Ezugwu EO, Wang ZM (1997) Titanium alloys and their machinability: a review. J Mater Process Technol 68:262-274. https://doi.org/10.1016/S0924-0136(96)00030-1

17. Fitseva V, Hanke S, dos Santos JF (2017) Influence of rotational speed on process characteristics in friction surfacing of Ti-6Al-4V. Mater Manuf Process 32:557-563. https://doi. org/10.1080/10426914.2016.1257799

18. Wang Y, Li C, Zhang Y, Li B, Yang M, Zhang X, Guo S, Liu G (2016) Experimental evaluation of the lubrication properties of the wheel/workpiece interface in MQL grinding with different nanofluids. Tribol Int 99:198-210. https://doi. org/10.1016/J.TRIBOINT.2016.03.023

19. Sutherland JW, Kulur VN, King NC, von Turkovich BF (2000) An experimental investigation of air quality in wet and dry turning. CIRP Ann Manuf Technol 49:61-64. https://doi. org/10.1016/S0007-8506(07)62896-0

20. Bianchi EC, Rodriguez RL, Hildebrandt RA, Lopes JC, de Mello HJ, da Silva RB, de Aguiar PR (2018) Plunge cylindrical grinding with the minimum quantity lubrication coolant technique assisted with wheel cleaning system. Int J Adv Manuf Technol 95(5-8):2907-2916. https://doi.org/10.1007/s0017 0-017-1396-5

21. Bianchi EC, Sato BK, Sales AR, Lopes JC, de Mello HJ, de Angelo Sanchez LE, Diniz AE, Aguiar PR (2018) Evaluating the effect of the compressed air wheel cleaning in grinding the AISI 4340 steel with CBN and MQL with water. Int J Adv Manuf Technol 95(5-8):2855-2864. https://doi.org/10.1007/s00170-017-1433-4

22. Bianchi EC, Rodriguez RL, Hildebrandt RA, Lopes JC, de Mello HJ, de Aguiar PR, da Silva RB, Jackson MJ (2019) Application of the auxiliary wheel cleaning jet in the plunge cylindrical grinding with minimum quantity lubrication technique under various flow rates. Proc Inst Mech Eng Part B J Eng Manuf 233(4):11441156. https://doi.org/10.1177/0954405418774599

23. Lopes JC, Ventura CE, Rodriguez RL, Talon AG, Volpato RS, Sato BK, de Mello HJ, de Aguiar PR, Bianchi EC (2018) Application of minimum quantity lubrication with addition of water in the grinding of alumina. Int J Adv Manuf Technol 97(5-8):19511959. https://doi.org/10.1007/s00170-018-2085-8

24. de Martini Fernandes L, Lopes JC, Ribeiro FS, Gallo R, Razuk HC, de Angelo Sanchez LE, de Aguiar PR, de Mello HJ, Bianchi EC (2019) Thermal model for surface grinding application. Int J Adv Manuf Technol 104(5-8):2783-2793. https://doi.org/10.1007/ s00170-019-04101-6

25. Rodriguez RL, Lopes JC, Hildebrandt RA, Perez RR, Diniz AE, de Ângelo Sanchez LE, Rodrigues AR, de Mello HJ, de Aguiar PR, Bianchi EC (2019) Evaluation of grinding process using simultaneously MQL technique and cleaning jet on grinding wheel surface. J Mater Process Technol 271:357-367. https://doi. org/10.1016/j.jmatprotec.2019.03.019
26. Lopes JC, Ventura CE, Fernandes LD, Tavares AB, Sanchez LE, de Mello HJ, de Aguiar PR, Bianchi EC (2019) Application of a wheel cleaning system during grinding of alumina with minimum quantity lubrication. Int J Adv Manuf Technol 102(1-4):333-341. https://doi.org/10.1007/s00170-018-3174-4

27. Fragoso KM, Francelin AP, Lopes JC, de Angelo Sanchez LE, de Melo HJ, Lodi AA, Aguiar PR, Bianchi EC (2019) Application of CAMQL technique on external cylindrical grinding of AISI 4340 steel with CBN grinding wheel. Mater Riode Janeiro. https://doi. org/10.1590/s1517-707620190003.0760

28. Javaroni RL, Lopes JC, Sato BK, Sanchez LE, Mello HJ, Aguiar PR, Bianchi EC (2019) Minimum quantity of lubrication (MQL) as an eco-friendly alternative to the cutting fluids in advanced ceramics grinding. Int J Adv Manuf Technol 103(5-8):2809-2819. https ://doi.org/10.1007/s00170-019-03697-z

29. Sato BK, Sales AR, Lopes JC, Sanchez LE, Mello HJ, Aguiar PR, Bianchi EC (2019) Influence of water in the MQL technique in the grinding of steel AISI 4340 using CBN wheels. REM Int Eng J 71(3):391-396. https://doi.org/10.1590/0370-44672017710152

30. Rodriguez RL, Lopes JC, Mancini SD, de Ângelo Sanchez LE, de Almeida Varasquim FM, Volpato RS, de Mello HJ, de Aguiar PR, Bianchi EC (2019) Contribution for minimization the usage of cutting fluids in CFRP grinding. Int J Adv Manuf Technol 103(14):487-497. https://doi.org/10.1007/s00170-019-03529-0

31. Lopes JC, Fragoso KM, Garcia MV, Ribeiro FS, Francelin AP, de Angelo Sanchez LE, Rodrigues AR, de Mello HJ, Aguiar PR, Bianchi EC (2019) Behavior of hardened steel grinding using MQL under cold air and MQL CBN wheel cleaning. Int J Adv Manuf Technol 105(10):4373-4387. https://doi.org/10.1007/ s00170-019-04571-8

32. de Moraes DL, Garcia MV, Lopes JC, Ribeiro FS, de Angelo Sanchez LE, Foschini CR, de Mello HJ, Aguiar PR, Bianchi EC (2019) Performance of SAE 52100 steel grinding using MQL technique with pure and diluted oil. Int J Adv Manuf Technol 105(10):4211-4223. https://doi.org/10.1007/s00170-019-04582 $-5$

33. Francelin RP, Costa WB, Lopes JC, Francelin AP, Mello HJ, Aguiar PR, Bianchi EC (2018) Evaluation of the oil flow using the MQL technique applied in the cylindrical plunge grinding of AISI 4340 steel with CBN grinding wheel. REM Int Eng J 71(3):397402. https://doi.org/10.1590/0370-44672017710139

34. Sadeghi MH, Haddad MJ, Tawakoli T, Emami M (2009) Minimal quantity lubrication-MQL in grinding of Ti-6Al-4V titanium alloy. Int J Adv Manuf Technol. 44(5-6):487-500. https://doi. org/10.1007/s00170-008-1857-y

35. Paul S, Chattopadhyay AB (2006) Environmentally conscious machining and grinding with cryogenic cooling. Mach Sci Technol 10:87-131. https://doi.org/10.1080/10910340500534316

36. Mukhopadhyay M, Kundu PK (2019) Improving grindability of Ti-6Al-4V using an economic and environmental friendly drop by drop delivery technique. Mater Tod Proc. https://doi. org/10.1016/j.matpr.2019.09.072

37. Kundu A, Mukhopadhyay M, Mahata S, Banerjee A, Mandal B, Das $S$ (2018) Grinding Titanium grade 1 alloy with an alumina wheelusing soap water. Proc Manuf 1(20):338-343. https://doi. org/10.1016/j.promfg.2018.02.049

38. Ghorai A, Mukhopadhyay M, Kundu PK, Das S (2019) Experimental investigation on enhancing grindability of Ti-6Al-4V under varying coolant concentration. J Assoc Eng India 89:47-56. https ://doi.org/10.22485/jaei/2019/v89/i1-2/185674

39. Venugopal KA, Paul S, Chattopadhyay AB (2007) Growth of tool wear in turning of Ti-6Al-4V alloy under cryogenic cooling. Wear 262:1071-1078. https://doi.org/10.1016/J.WEAR.2006.11.010

40. Venugopal KA, Paul S, Chattopadhyay AB (2007) Tool wear in cryogenic turning of Ti-6AI-4V alloy. Cryogenics 47:12-18. https ://doi.org/10.1016/J.CRYOGENICS.2006.08.011 
41. An QL, Fu YC, Xu JH, Xu HJ (2006) The cooling effects of cryogenic pneumatic mist jet impinging in grinding of titanium alloy. Key Eng Mater 304-305:575-578. https://doi.org/10.4028/ www.scientific.net/KEM.304-305.575

42. Teicher U, Ghosh A, Chattopadhyay AB, Künanz K (2006) On the grindability of titanium alloy by brazed type monolayered superabrasive grinding wheels. Int J Mach Tools Manuf 46:620 622. https://doi.org/10.1016/J.IJMACHTOOLS.2005.07.012

43. Teicher U, Künanz K, Ghosh A, Chattopadhyay AB (2008) Performance of diamond and CBN single-layered grinding wheels in grinding titanium. Mater Manuf Process 23:224-227. https://doi. org/10.1080/10426910701860541

44. Elanchezhian J, Kumar MP, Manimaran G (2015) Grinding titanium Ti-6Al-4V alloy with electroplated cubic boron nitride wheel under cryogenic cooling. J Mech Sci Technol 29:48854890. https://doi.org/10.1007/s12206-015-1036-7

45. Gupta K, Laubscher RF (2017) Sustainable machining of titanium alloys: a critical review. Proc Inst Mech Eng Part B J Eng Manuf 231:2543-2560. https://doi.org/10.1177/0954405416634278

46. Shaw MC (1996) Principles of abrasive processing. Oxford University Press, Clarendon

47. Chen X, Rowe WB (1996) Analysis and simulation of the grinding process. Part I: generation of the grinding wheel surface. IntJ Mach Tools Manuf 36:871-882. https://doi.org/10.1016/08906955(96)00116-2
48. Kundu A, Mukhopadhyay M, Banerjee A, Mahata S, Mandal B, Das $S$ (2018) Grinding of titanium using alumina and silicon carbide wheel. J Assoc Eng India 88(1/2):53-63. https://doi. org/10.22485/jaei\%2F2018\%2Fv88\%2Fi1-2\%2F174926

49. Mukhopadhyay M, Kundu PK (2018) Development of a simple and efficient delivery technique for grinding Ti-6Al-4V. Int J Mach Mach Mater 20:345-357. https://doi.org/10.1504/IJMMM .2018.10013115

50. Mukhopadhyay M, Kundu PK, Chatterjee S, Das S (2019) Impact of dressing infeed on silicon carbide wheel for grinding Ti-6Al-4V. Mater Manuf Process 34(1):54-60. https://doi. org/10.1080/10426914.2018.1532588

51. Mukhopadhyay M, Kundu PK (2018) Optimization of dressing infeed of alumina wheel for grinding Ti-6Al-4V. Mater Manuf Process 33(13):1453-1458. https://doi.org/10.1080/10426 914.2018 .1453164

Publisher's Note Springer Nature remains neutral with regard to jurisdictional claims in published maps and institutional affiliations. 